\title{
EDITORIAL
}

\section{THE TIME HAS ARRIVED TO MEET THE CHALLENGE OF ALZHEIMER'S DISEASE IN EUROPE}

\author{
R.W. JONES
}

Professor, Director, RICE (The Research Institute for the Care of Older People), Royal United Hospital, Bath BA1 3NG, UK

The IMPACT (Important Perspectives on Alzheimer's Care and Treatment) survey was undertaken to assess awareness of, and attitudes towards, dementia in general and Alzheimer's disease (AD) in particular among key stakeholders from 5 European countries: France, Germany, Italy, Spain and the United Kingdom. The results of the survey are presented in a collection of 7 articles that comprise the supplement appearing simultaneously with this issue (1-7). Survey respondents numbered more than 1700 , including 950 members of the general population, 500 physicians, 250 caregivers and 50 payors (health policy managers and decision-makers). Although the survey, which was conducted online and without randomised sampling, had methodological limitations, its results are nonetheless of major interest to every professional working with people with dementia, as well as all those whose lives are affected, whether directly or indirectly, by AD.

The survey, as might be expected, reveals differences amongst the 5 countries, reflecting regional variation across Europe, and differences between the various stakeholder groups, reflecting their distinct perspectives. These differences are important, and they are highlighted and discussed in each of the articles within the supplement. However, what emerges clearly from the IMPACT survey, encompassing all stakeholder groups and all participating countries, are several overarching themes that create a vivid picture of current European perceptions and beliefs about AD.

The first main theme is this: awareness of $\mathrm{AD}$ and the problems it poses is greater than it has ever been. The overwhelming majority of respondents from all stakeholder groups recognise that AD is not a feature of normal ageing, believe that it is a serious societal problem and appreciate the extent of the burden this disease imposes on caregivers and family members. Indeed, AD is now on par with cancer as the most feared disease, and the disease feared by most. Respondents are also aware that most people have difficulty distinguishing cognitive changes associated with normal ageing from those suggestive of incipient $\mathrm{AD}$ and identify this as one of the contributing factors to delayed diagnosis.

The second major theme is this: much more needs to be done to effectively address the challenges posed by AD. Ranging across all topics covered by the IMPACT survey, the prevailing attitude of respondents was that more needs to be done-to educate the public, particularly with regard to recognising early signs; to support caregivers and families; to promote and Received July 2, 2010

Accepted for publication July 9, 2010 facilitate earlier diagnosis; to provide comprehensive treatment; and to fund research. All stakeholder groups, including payors, felt that $\mathrm{AD}$ is underdiagnosed and undertreated, and expressed concern that governments do not view $\mathrm{AD}$ as a health care priority. Perhaps the only exception with respect to the theme of needing to do more was with regard to screening. Although large majorities of the general public and caregivers favoured more screening, physicians were divided on this issue because of concerns about accuracy and cost-effectiveness.

The third major theme is this: quality improvement is essential if we are to win the battle against AD. All respondents agreed that we need more effective therapies; physicians and payors recognised the need for better screening tools; the general public and caregivers highlighted the need for more effective educational programmes and methods for accurate, early diagnosis. However, there was no evidence of increased awareness about AD clinical trials, and awareness of accessibility to such trials was very low amongst both caregivers and physicians in all countries surveyed. As a clinical researcher, I was particularly impressed with this lack of awareness about trials in contrast to the expressed willingness of physicians to refer patients to participate in studies and of caregivers to support such participation. There is clearly both a need and an opportunity for us to improve the quality of clinical trial recruitment.

The resonance of these common themes in the IMPACT survey data, punctuated by examples of contrasting opinions amongst various stakeholder groups and/or countries, provides a fascinating glimpse of how Europeans perceive AD today. I encourage you to examine these IMPACT data, presented concisely yet comprehensively in the 7 articles included in the accompanying supplement. I hope you will be impressed, as I have been, with the evidence of rapidly growing awareness of $\mathrm{AD}$ and its consequences, and the increasing stakeholder demand for earlier diagnosis, more effective treatment and better support for caregivers. Meeting these challenges will require a major investment of public and private resources; a widespread programme of education for the general public, health care professionals, patients and their families; quality improvement initiatives within health care systems; and a more concerted research effort to discover more effective therapies and better preventive strategies. At the same time, we need to communicate a more realistic image of $\mathrm{AD}$, emphasising the role and value of currently available treatments. There is much 


\section{EDITORIAL}

that we can offer our patients, their caregivers and their families, who are all more prepared today to meet the challenge of $\mathrm{AD}$ than ever before.

Disclosure: Professor Jones participated in the design of the survey and the analysis of survey data, and is the lead author of 2 of the manuscripts. The IMPACT survey was sponsored by Pfizer Inc and Eisai Inc. Editorial support was provided by Bill Kadish, MD, of PAREXEL and was funded by Pfizer Inc and Eisai Inc.

\section{References}

1. Jones RW, Mackell J, Berthet K, Knox S. Assessing attitudes and behaviours surrounding Alzheimer's disease in Europe: key findings of the Important Perspectives on Alzheimer's Care and Treatment (IMPACT) survey. J Nutr Health Aging. 2010;14(7):525-530
2. Wortmann M, Andrieu S, Mackell J, Knox S. Evolving attitudes to Alzheimer's disease among the general public and caregivers in Europe: findings from the IMPACT survey. J Nutr Health Aging. 2010;14(7):531-536

3. Martinez-Lage P, Frölich L, Knox S, Berthet K. Assessing physicians' attitudes and perceptions of Alzheimer's disease across Europe. J Nutr Health Aging. 2010;14(7):537-544

4. Robinson L, Vellas B, Knox S, Lins K. Clinical practice patterns of generalists and specialists in Alzheimer's disease: what are the differences, and what difference do they make? J Nutr Health Aging. 2010;14(7):545-552

5. Forette F, Padovani A, Berthet K, Knox S. Implications of the IMPACT survey for payors across Europe. J Nutr Health Aging. 2010;14(7):553-557

6. Bond J, Graham N, Padovani A, Mackell J, Knox S, Atkinson J. Screening for cognitive impairment, Alzheimer's disease and other dementias: opinions of European caregivers, payors, physicians and the general public. J Nutr Health Aging. 2010;14(7):558-562

7. Jones RW, Andrieu S, Knox S, Mackell J. Physicians and caregivers: ready and waiting for increased participation in clinical research. J Nutr Health Aging. 2010;14(7):563-568 